\title{
Efeitos da temperatura e do teor de água na qualidade de grãos de canola durante o armazenamento
}

\section{Effects of temperature and humidity on canola grain quality during storage}

\author{
Camila Fontoura Nunes ${ }^{1}$ \\ Elton Pilar Medeiros ${ }^{2}$ \\ Luana Haeberlin ${ }^{3}$ \\ Nairiane Bilhalva ${ }^{4}$ \\ Ricardo Tadeu Paraginski ${ }^{5}$
}

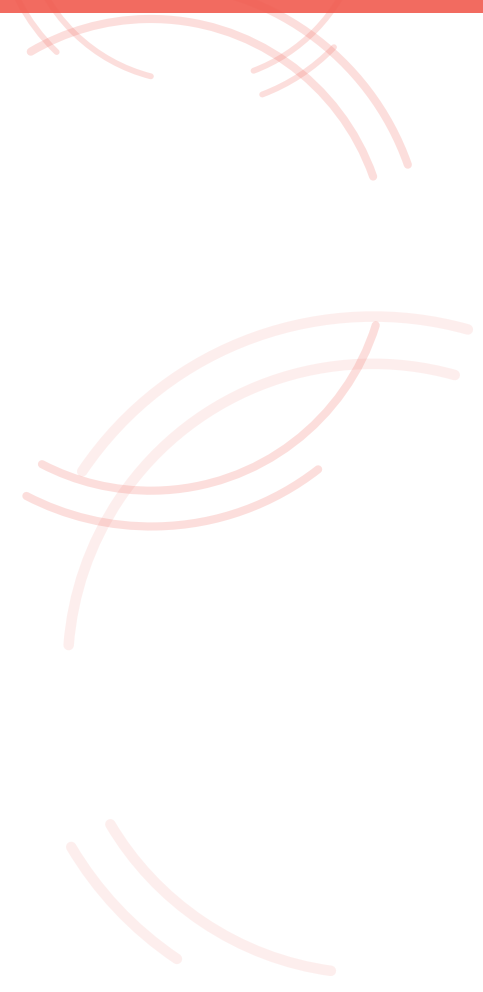

\section{RESUMO}

A canola apresenta elevado potencial de utilização no Brasil como alternativa para sistemas produtivos de inverno. Dentre os fatores que afetam a qualidade de armazenamento da canola, a temperatura e a umidade dos grãos são os principais, pois estando inadequados aceleram as reações bioquímicas e metabólicas dos grãos que acarretam em perdas. Assim, considerando a crescente produção de canola, o objetivo do trabalho foi determinar os efeitos da umidade dos grãos, temperatura e tempo de armazenamento seguras para manutenção da qualidade de grãos de canola armazenados. Os grãos foram armazenados por um período de 180 dias com os teores de água de 8, 10, 12 e 14\% nas temperaturas de 7, 17 e $27^{\circ} \mathrm{C}$, e foram avaliados os parâmetros de qualidade tecnológicos de grãos. Os resultados indicaram que as temperaturas de 17 e $27^{\circ} \mathrm{C}$ ocasionaram as maiores reduções de qualidade nos parâmetros avaliados dos grãos armazenadas com 12 e $14 \%$ de umidade. A temperatura de $27^{\circ} \mathrm{C}$ ocasionou perdas de qualidade nas amostras armazenadas com $10 \%$ de umidade. Na temperatura de $7^{\circ} \mathrm{C}$ ocorreu melhor conservação das sementes nos teores de água de 8, 10 e 12\% durante 180 dias de armazenamento.

Palavras-chave: Secagem. Deterioração. Qualidade. Defeitos. Comercialização.

1 Acadêmica do Curso de Engenharia Agrícola do Instituto Federal Farroupilha - Campus Alegrete e da Universidade Federal do Pampa | camilafnunes_@hotmail.com

2 Técnico Administrativo em Educação do Instituto Federal Farroupilha - Campus Alegrete

| elton.medeiros@iffarroupilha.edu.br

3 Acadêmica do Curso de Engenharia Agrícola do Instituto Federal Farroupilha - Campus Alegrete e da Universidade Federal do Pampa | luana.haeberlin@gmail.com

4 Acadêmica do Curso de Engenharia Agrícola do Instituto Federal Farroupilha - Campus Alegrete

e da Universidade Federal do Pampa | nairianeb@gmail.com

5 Instituto Federal Farroupilha - Campus Alegrete | ricardo.iffar@gmail.com 


\section{Efeitos da temperatura e do teor de água na qualidade de grãos de canola durante o armazenamento}

Effects of temperature and humidity on canola grain quality during storage

\section{ABSTRACT}

The canola has a high potential for use in Brazil as an alternative to winter production systems. Among the factors that affect the quality of storage of canola, the temperature and humidity of the grains are the main ones, because if they are inadequate accelerate the biochemical and metabolic reactions of the grains that cause losses. Thus, considering the growing production of canola, the objective of the work was to determine the effects of grain moisture, temperature and safe storage time for maintaining the quality of stored grain grains. The grains were stored for a period of 180 days with water contents of $8,10,12$ and $14 \%$ at temperatures of 7,17 and $27^{\circ} \mathrm{C}$, and the technological parameters of grain quality were adopted. The results indicated that the temperatures of 17 and $27^{\circ} \mathrm{C}$ caused the greatest quality reductions in the parameters emitted from the grains stored with 12 and $14 \%$ humidity. The temperature of $27^{\circ} \mathrm{C}$ caused quality losses in those stored at $10 \%$ humidity. At the temperature of $7^{\circ} \mathrm{C}$, the best conservation of the seeds occurred in the water contents of 8,10 and $12 \%$ during 180 days of storage.

Keywords: Drying. Deterioration. Quality. Defects. Commercialization 


\section{Introdução}

A canola (Brassica napus L. var. oleifera) é a terceira oleaginosa mais produzida no mundo com grande importância na produção de óleo vegetal comestível (TOMM, 2007), na produção de biocombustível e na alimentação animal. A cultura possui elevado valor devido ao poder nutricional do seu óleo, principalmente por possuir o menor teor de gordura saturada dentre os óleos vegetais. A cultura necessita de temperaturas amenas para sua produção, sendo principalmente cultivada em climas temperados (TOMM, 2007). O país com maior produção da oleaginosa é o Canadá, e o Brasil possui uma produtividade inexpressiva em âmbito mundial, sendo que o Rio Grande do Sul é o estado brasileiro com maior cultivo de canola.

O cultivo da canola é relativamente novo no cenário produtivo brasileiro e nos últimos anos vêm conquistando o investimento dos produtores. Porém, a falta de conhecimentos científicos voltados para a produção dessa oleaginosa tem dificultado a expansão da sua produção no país. A cultura tem sido empregada com várias finalidades na agricultura brasileira, tais como melhoramento de solo e inibição de pragas e moléstias na rotação de culturas, forragem verde para alimentação animal, produção industrial de biocombustível, alimentação humana através do seu óleo e o subproduto da extração está sendo destinado para formulação de rações animais.

A técnica de armazenagem objetiva manter as características que os grãos possuem imediatamente após o pré-processamento, tais como a viabilidade de sementes, a qualidade de moagem e as propriedades nutritivas dos grãos (BROOKER et al., 1992), conservando-os em perfeitas condições técnicas para redistribuí-los posteriormente (PUZZI, 1999). A necessidade de conhecimentos sobre conservação de grãos fica evidenciada quando são analisadas as potencialidades brasileiras de produção agrícola e são verificadas as perdas de grande parte do que se produz em função de deficiências em infraestrutura, como falta de unidades de secagem e armazenamento inadequadas, juntamente com processos e operações ineficientes.

De acordo com Reed et al. (2007) e Park et al. (2012), vários fatores interferem na qualidade dos grãos durante o armazenamento, como umidade e temperatura dos grãos, temperatura e umidade do ar, presença de grãos quebrados, matérias estranhas e impurezas, ataque de insetos, ácaros e microrganismos, manejo tecnológico e tempo de armazenamento. A temperatura é um dos principais fatores que interfere na qualidade de armazenamento de grãos (PARK et al., 2012; REHMAN et al., 2002; REED et al., 2007), sendo que nos últimos anos vem crescendo a utilização da tecnologia de resfriamento artificial em grãos, buscando preservar a qualidade do produto por períodos mais elevados e reduzir a deterioração dos grãos.

Ao estudar diferentes condições de temperatura e teor de umidade para armazenamento de grãos de milho, Paraginski et al. (2015) encontraram resultados que as maiores alterações de teor de água, peso de mil grãos, germinação, condutividade elétrica e perfil de ácidos graxos ocorrem nos grãos armazenados nas temperaturas mais elevadas, principalmente a 25 e $35^{\circ} \mathrm{C}$, indicando que o tempo de armazenamento seguro dos grãos nessas condições é menor quando comparado ao armazenamento em temperaturas mais baixas. Segundo Faroni (1998), há um aumento de intensidade de respiração, proporcional ao aumento da temperatura, que fica na dependência do teor de umidade dos grãos e esta afirma que o teor de umidade do grão limita, além das atividades metabólicas do grão, o desenvolvimento de bactérias, actinomicetes, leveduras, fungos, ácaros e insetos que são os principais agentes de deterioração dos grãos armazenados.

Considerando esses fatores, verificamos a necessidade de melhorar as práticas de armazenamento, procurando condições ideais para garantir a qualidade inicial da massa de grãos de canola ao longo do armazenamento. Assim, o objetivo no trabalho foi avaliar os efeitos dos teores de umidade de armazenamento de $8,10,12$ e $14 \%$ durante o tempo de armazenamento de 180 dias nas temperaturas 
de 7,17 e $27^{\circ} \mathrm{C}$ de grãos de canola buscando identificar condições seguras de armazenamento para auxiliar na tomada de decisão do produtor.

\section{Material e métodos}

O trabalho foi realizado nos Laboratórios de Classificação de Grãos e de Fitotecnia do Instituto Federal de Educação, Ciência e Tecnologia Farroupilha - Campus Alegrete - Rio Grande do Sul. Foram utilizadas grãos de canola (Brassica napus L. var. olífera), fornecidas pela Agropecuária Trombetta do município de São Francisco de Assis, RS, Brasil, latitude 29³3'56" S, longitude 5454'3" O e altitude de 155 metros. Os grãos foram colhidos mecanicamente e a limpeza realizada manualmente com conjunto de peneiras de furos circulares de $3,0 \mathrm{~mm}$ e $1,8 \mathrm{~mm}$ de diâmetro no Laboratório de Classificação de Grãos.

Após a limpeza, as sementes foram submetidas à secagem artificial em estufa com temperatura do ar de $40^{\circ} \mathrm{C}$ até a obtenção das umidades de 8, 10, 12 e 14\%, para iniciar o armazenamento. As sementes, após a obtenção das umidades desejadas, foram armazenadas em sacos de polietileno com dimensões de $30 \times 30 \mathrm{~cm}$, espessura de filme plástico de 0,2 mm, capacidade para mil gramas e vedadas com máquina Webomatic. Depois de embaladas, as sementes foram dispostas em pilhas em câmaras de temperatura controlada, do tipo B.O.D. nas temperaturas de 7,17 e $27^{\circ} \mathrm{C}$ durante 180 dias.

I 1. Teor de água: Para determinação do teor de água, foi utilizado o método de estufa com circulação de ar, à temperatura de $105 \pm 1^{\circ} \mathrm{C}$, durante $24 \mathrm{~h}$, em três repetições, de acordo com recomendações da American Society of Agricultural Engineers (ASAE, 2000). Os resultados foram expressos em porcentagem (\%).

I 2. Peso de 1000 grãos: 0 peso de 1000 sementes foi determinado com contagem de 8 repetições de 100 sementes e pesagem em balança analítica (Brasil, 2009). Os resultados foram expressos em gramas.

I 3. Perda de matéria seca: 0 peso volumétrico dos grãos foi determinado com pesagem de 8 repetições em balança Dalle molle e pesagem em balança analítica. Com os resultados obtidos pelo peso volumétrico foi determinada a perda de massa específica aparente ao longo do tempo de armazenamento.

I 4. Percentual de grãos mofados: Para identificação dos defeitos, foram pesadas três repetições de 25 gramas, em que foram identificados e pesados os seguintes defeitos: sementes amassadas e quebradas, sementes germinadas, sementes chochas, sementes verdes e sementes mofadas, além das matérias estranhas e impurezas presente nas amostras.

I 5. PH dos grãos: o pH das sementes, realizado com metodologia adaptada de Rehman et al. (2002), foi determinado pela água de hidratação de 50 sementes submersos por $75 \mathrm{~mL}$ de água destilada com pH conhecido, mantida por 24 horas em germinador a $20^{\circ} \mathrm{C}$, e determinado em um eletrodo de vidro $\mathrm{pH}$ metro (Pye Unicam, Inglaterra). Os resultados médios foram obtidos pela diferença entre o pH final da solução e o pH inicial da água de hidratação sob pH base de 5,0.

O experimento foi realizado utilizando experimentação trifatorial (temperatura $x$ teor de água das sementes $\mathrm{x}$ tempo de armazenamento). Os dados foram submetidos à análise de variância, de acordo com o teste $F$, a $5 \%$ de probabilidade com uso do ASSISTAT 7.7 beta (Silva \& Azevedo, 2002) e os gráficos foram elaborados com o uso do SigmaPlor 13.0 (SIGMAPLOT, 2015). 


\section{Resultados e discussão}

Os resultados de teores médios de umidade (Figura 1) indicaram que os grãos armazenados com índice de água de 8\% apresentaram uma redução de umidade aos 90 dias de armazenamento, mais significativamente no tratamento a $27^{\circ} \mathrm{C}$, porém aos 180 dias, o teor de água dos grãos não possuiu diferença significativa entre os três tratamentos. Nos grãos armazenados com índice de água de $10 \%$ de umidade também ocorreu uma redução aos 90 dias de armazenamento. Porém, o índice de água aos 180 dias, no tratamento a $27^{\circ} \mathrm{C}$ foi o que se apresentou significativamente maior que dos tratamentos a 7 e $17^{\circ} \mathrm{C}$, que sofreram uma redução. Já nos grãos armazenados com índice de água de $12 \%$, aos 90 dias apresentaram um acréscimo no teor de água que ao fim não diferiu significativamente as taxas de umidade entre os tratamentos. Nos grãos armazenados a 14\%, ocorreu acréscimo de umidade no tratamento a $17^{\circ} \mathrm{C}$ aos 90 dias.

Figura 1 - Efeitos do tempo de armazenamento no teor de água (\%) de grãos de canola armazenadas nos teores de água de $8 \%(A), 10 \%$ (B), $12 \%$ (C) e $14 \%$ (D) nas temperaturas de 7,17 e $27^{\circ} \mathrm{C}$.
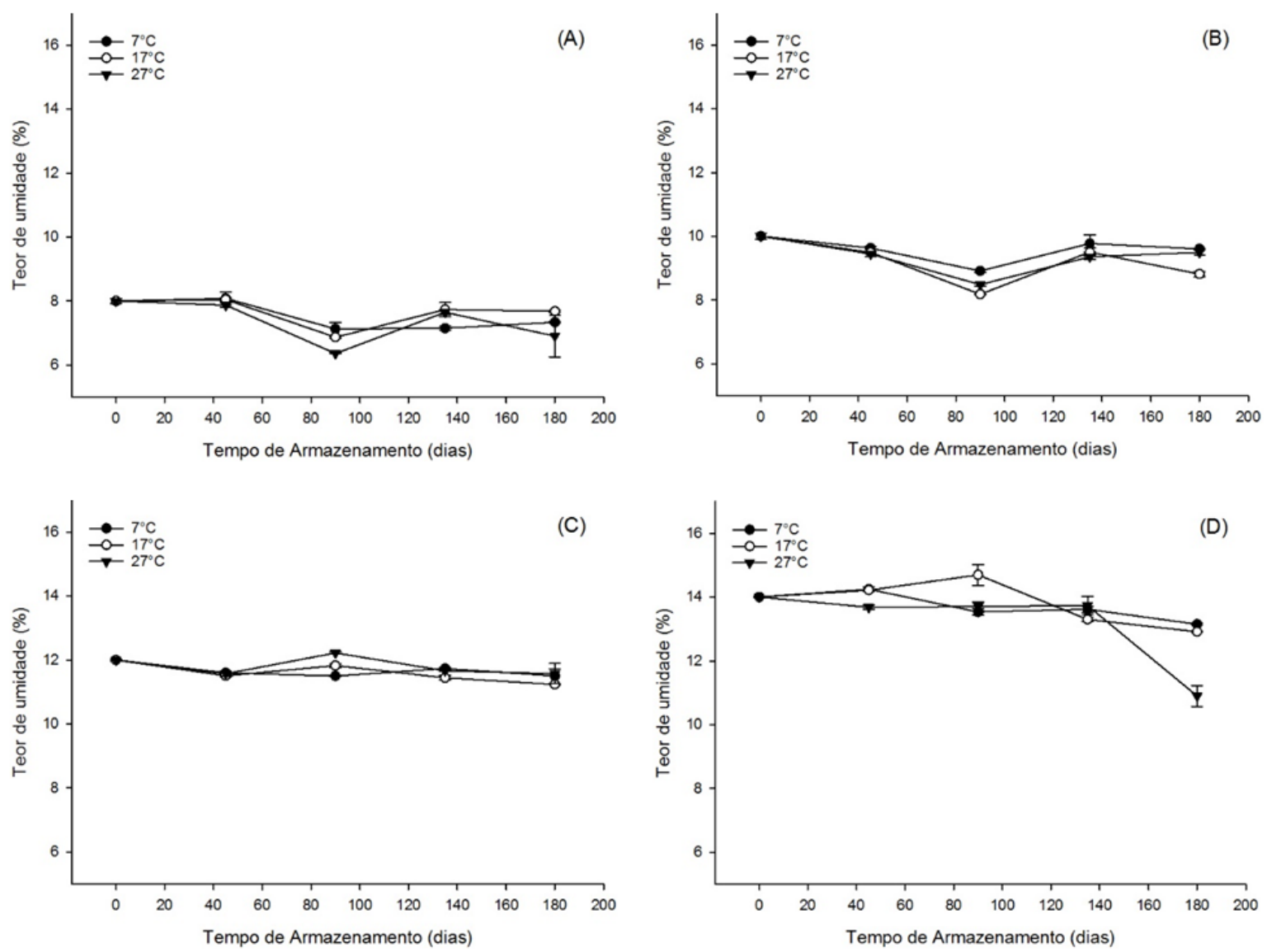

Fonte: elaborado pelo autor.

As oscilações no teor de água durante 0 armazenamento ocorrem devido às mudanças da umidade relativa do ar. Segundo Silva et al. (1995), quando a pressão de vapor da semente é maior que a pressão de vapor do ar circundante, ocorre o fenômeno de dessorção, havendo transferência de vapor de água para o ar, reduzindo, desta forma, a umidade das sementes. O equilíbrio higroscópico é influenciado pela composição química da semente, integridade física, estado sanitário, gradientes termo hídricos e operações de pós-colheita, dentre os quais a secagem e o armazenamento são as mais importantes (CARNEIRO et al., 2005). De acordo com Rios et al. (2003), o teor de água superior ao recomendado para o armazenamento seguro é uma das principais causas da perda das características tecnológicas 
dos grãos durante o armazenamento. Em estudos com diferentes condições de armazenamento de grãos de milho, Faroni et al. (2005) observaram decréscimo no teor de água dos grãos de milho, ao longo do período de armazenamento, para as temperaturas acima de $25^{\circ} \mathrm{C}$. 0 teor de água dos grãos variou de $13,5 \%$ base úmida (b.u.), no início do experimento, a 12,5 e 10,5\% b.u., para as temperaturas de 30 e $40^{\circ} \mathrm{C}$, respectivamente, depois de 180 dias de armazenamento.

Os resultados de peso de mil sementes dos grãos de canola armazenados durante 180 dias nas temperaturas de 7,17 e $27^{\circ} \mathrm{C}$ com teor de água de 8, 10, 12 e 14\% (Figura 2) mostram que ocorreu um decréscimo no peso de mil sementes durante os 180 dias de armazenamento, nos quatro teores de água estudados. Nos grãos que apresentavam teor de água de $8 \%$ houve uma queda de redução de massa aos 45 dias de armazenamento que se manteve, sem diferença significativa, até o fim dos 180 dias de armazenamento. 0 acréscimo de peso dos grãos armazenados com teor de água de 14\% na temperatura de $17^{\circ} \mathrm{C}$ aos 90 dias de armazenamento está atribuído ao aumento do teor de água apresentado, pois o peso dos grãos é a soma de massa úmida e massa seca, em que com o aumento do teor de água a massa úmida acresce, tornando maior o peso. Apesar das oscilações de peso de mil apresentadas durante os 180 dias de armazenamento, os resultados finais obtidos não apresentaram diferença entre as temperaturas de armazenamento empregadas.

Figura 2 - Efeito do tempo de armazenamento no peso de mil sementes (g) de canola armazenadas nos teores de água de $8 \%(A), 10 \%(B), 12 \%(C)$ e $14 \%(D)$ nas temperaturas de 7,17 e $27^{\circ} \mathrm{C}$.
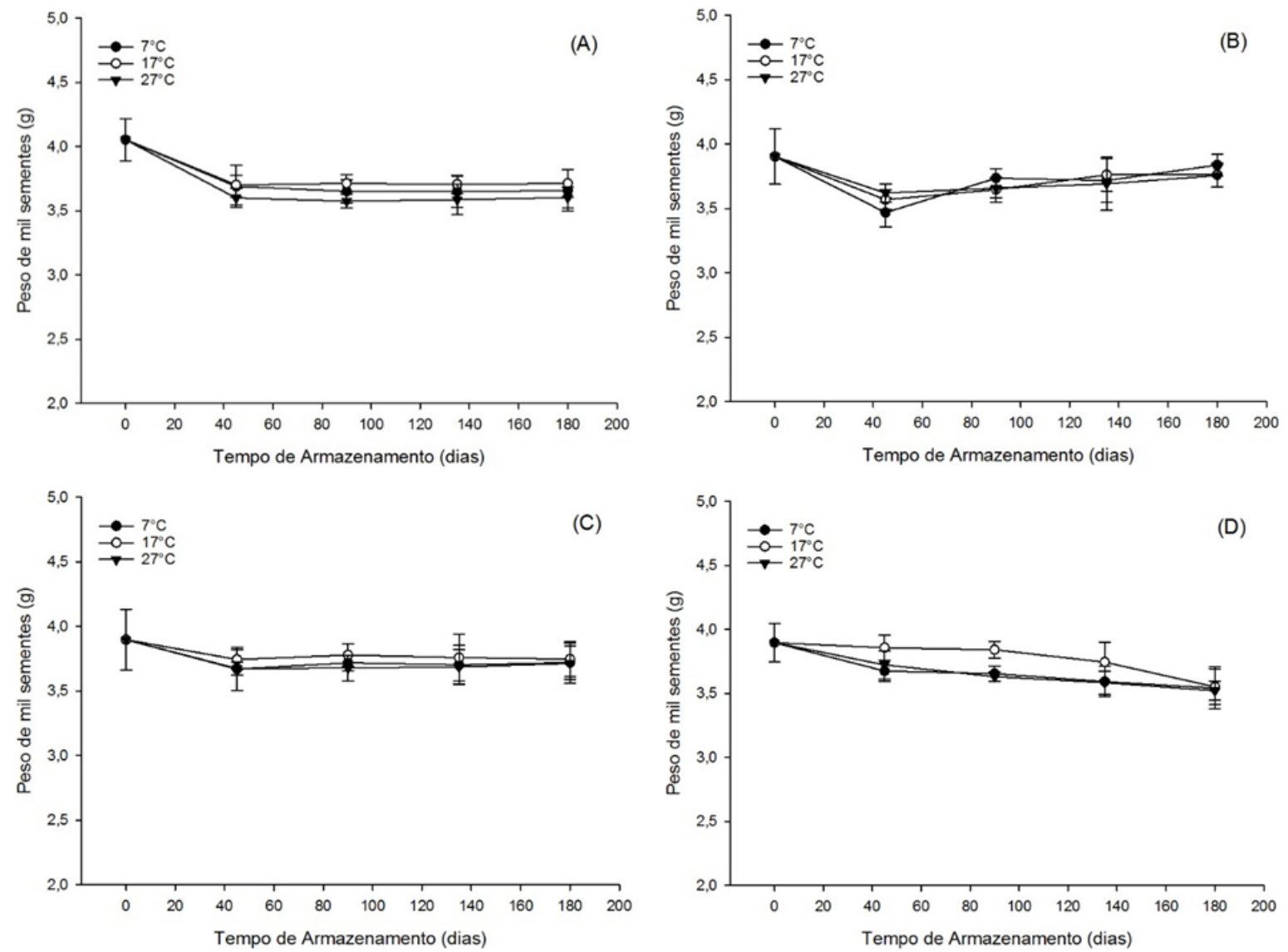

Fonte: elaborado pelo autor. 
Os resultados de perda de matéria seca dos grãos de canola armazenados durante 180 dias nas temperaturas de 7, 17 e $27^{\circ} \mathrm{C} \mathrm{com} \mathrm{teor} \mathrm{de} \mathrm{água} \mathrm{de} \mathrm{8,} \mathrm{10,} 12$ e 14\% (Figura 3) indicam que em todas as situações estudadas ocorreu perda de massa seca no armazenamento. Nos grãos armazenados com teor de água de 8\% não houve diferença significativa entre os tratamentos, sendo a perda de massa seca próxima a 1,15\% em 180 dias de armazenamento. Nos grãos armazenados com teor de água de $10 \%$ aos 180 dias de armazenamento, no tratamento a $27^{\circ} \mathrm{C}$, a perda de massa seca foi de aproximadamente $1,95 \%$, significativamente maior do que a perda de massa seca dos outros tratamentos de aproximadamente $0,8 \%$. Nos grãos armazenados com maior teor de água ( $12 \% \mathrm{e}$ $14 \%$ ) ocorreram maiores perdas de massa seca, nos 180 dias de armazenamento, e essas foram mais expressivas conforme 0 aumento da temperatura. Aos 180 dias, a perda total de massa seca nas amostras de grãos com teor de água de $12 \%$ foram de 1,81, 4,12 e 7,83\% para os tratamentos a 7 , 17 e $27^{\circ} \mathrm{C}$, respectivamente, e nas amostras de grãos com teor de água de $14 \%$ foram de $4,41,7,63$ e $13,80 \%$ para os tratamentos a 7,17 e $27^{\circ} \mathrm{C}$, respectivamente. Estes resultados comprovam que 0 desenvolvimento fúngico reduz a massa específica aparente e a massa específica seca das sementes.

Figura 3 - Efeito do tempo de armazenamento na perda de matéria seca (\%) de grãos de canola armazenados a $8 \%$ (A), $10 \%$ (B), $12 \%$ (C) e $14 \%$ (D) de umidade nas temperaturas de 7,17 e $27^{\circ} \mathrm{C}$.
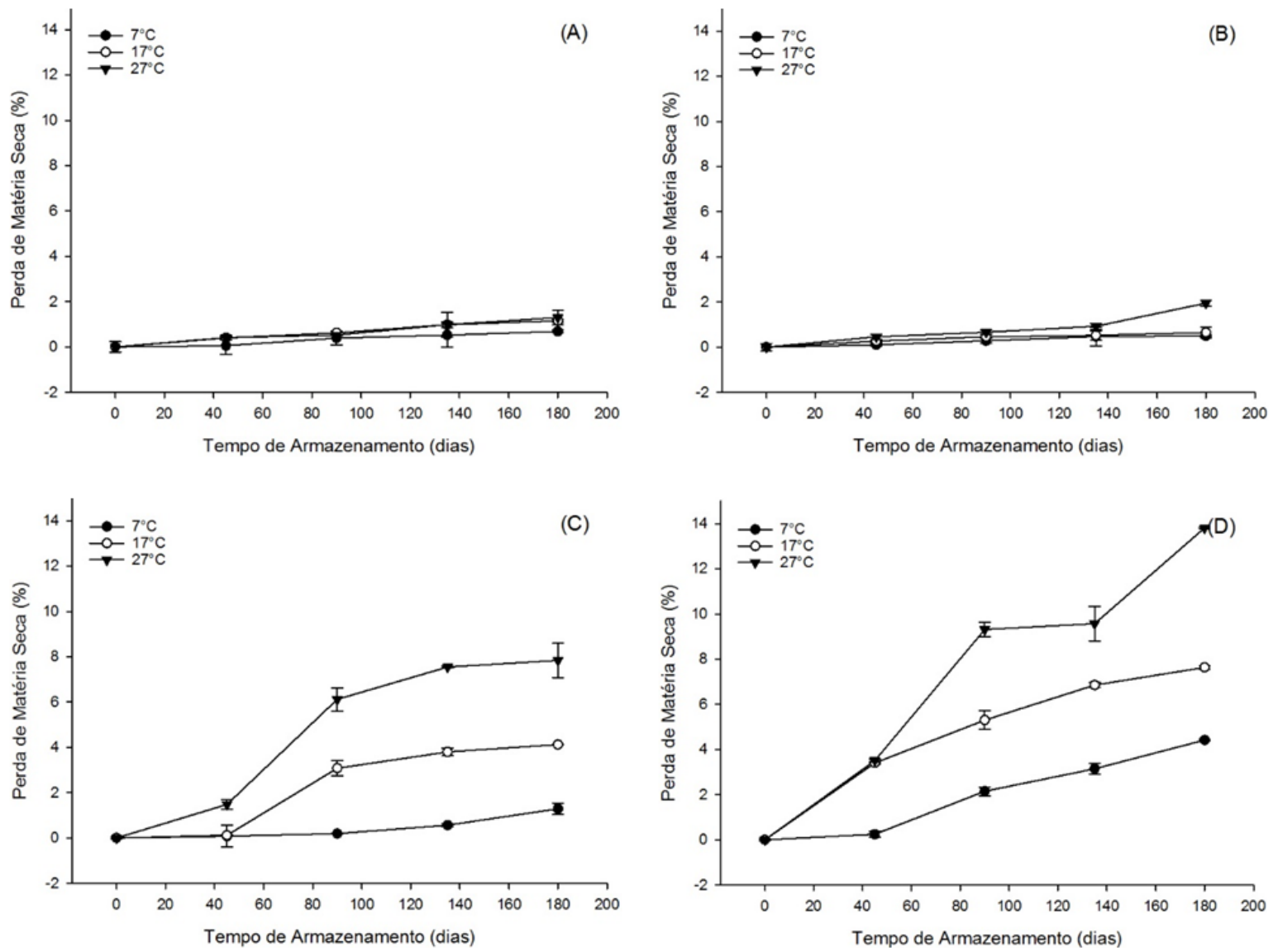

Fonte: elaborado pelo autor.

De acordo com Santos et al. (2012), ao avaliar a qualidade e a perda de matéria seca em grãos de milho armazenados em bolsas herméticas em diferentes temperaturas, observaram que as maiores taxas de redução ocorreram nos grãos armazenados com teor de água de 17,9\% em temperaturas de 25 e $35^{\circ} \mathrm{C}$. A redução da massa específica da matéria seca em grãos geralmente está associada a um aumento de volume devido ao ganho de água ou à perda de matéria seca. 
Os teores médios de grãos de canola mofados durante o armazenamento de 180 dias nas temperaturas de 7, 17 e $27^{\circ} \mathrm{C}$ com teor de água de 8, 10, 12 e 14\% (Figura 4) indicaram que para as amostras armazenadas com teor de água 8 e 10\%, o teor de grãos mofados não ultrapassou 0,5\%, nas três temperaturas avaliadas durante o período de 180 dias de armazenamento. No entanto, os grãos armazenados com teor de água de $12 \%$ na temperatura $27^{\circ} \mathrm{C}$, ao fim do período apresentaram incidência de grãos mofados de 4,22\%. Analisando o regulamento técnico de outras sementes, tais como milho (BRASIL, 2011), trigo (BRASIL, 2010), girassol e mamona (BRASIL, 1993), esta porcentagem de grãos mofados classificaria a amostra como fora de tipo por exceder o limite deste defeito, no entanto, ao comparar com o regulamento técnico para os grãos de soja (BRASIL, 2007), sendo considerado como grupo II, este teor de grãos mofados classificaria a amostra como padrão básico, não excedendo o limite de 6\%. Já nos grãos armazenados com teor de água de 14\%, obteve-se $100 \%$ da amostra mofada nas temperaturas de 27 e $17^{\circ} \mathrm{C}$ aos 90 e 180 dias de armazenamento, respectivamente.

O desenvolvimento fúngico é resultado de práticas inadequadas de armazenamento, principalmente temperatura e umidade inadequada, que podem levar ao desenvolvimento fúngico com a produção de micotoxinas que causam sérios riscos à saúde dos consumidores. Estudos realizados por Alencar et al. (2009) confirmaram que o processo de deterioração dos grãos de soja armazenados intensifica-se com a combinação de elevadas temperaturas e teores de água, os quais alteraram a classificação e a coloração do produto, devido, principalmente, ao desenvolvimento fúngico.

Figura 4 - Efeitos do tempo de armazenamento na incidência de grãos mofados (\%) de canola armazenados nos teores de água de $8 \%(A), 10 \%(B), 12 \%(C)$ e $14 \%(D)$ nas temperaturas de 7,17 e $27^{\circ} \mathrm{C}$.
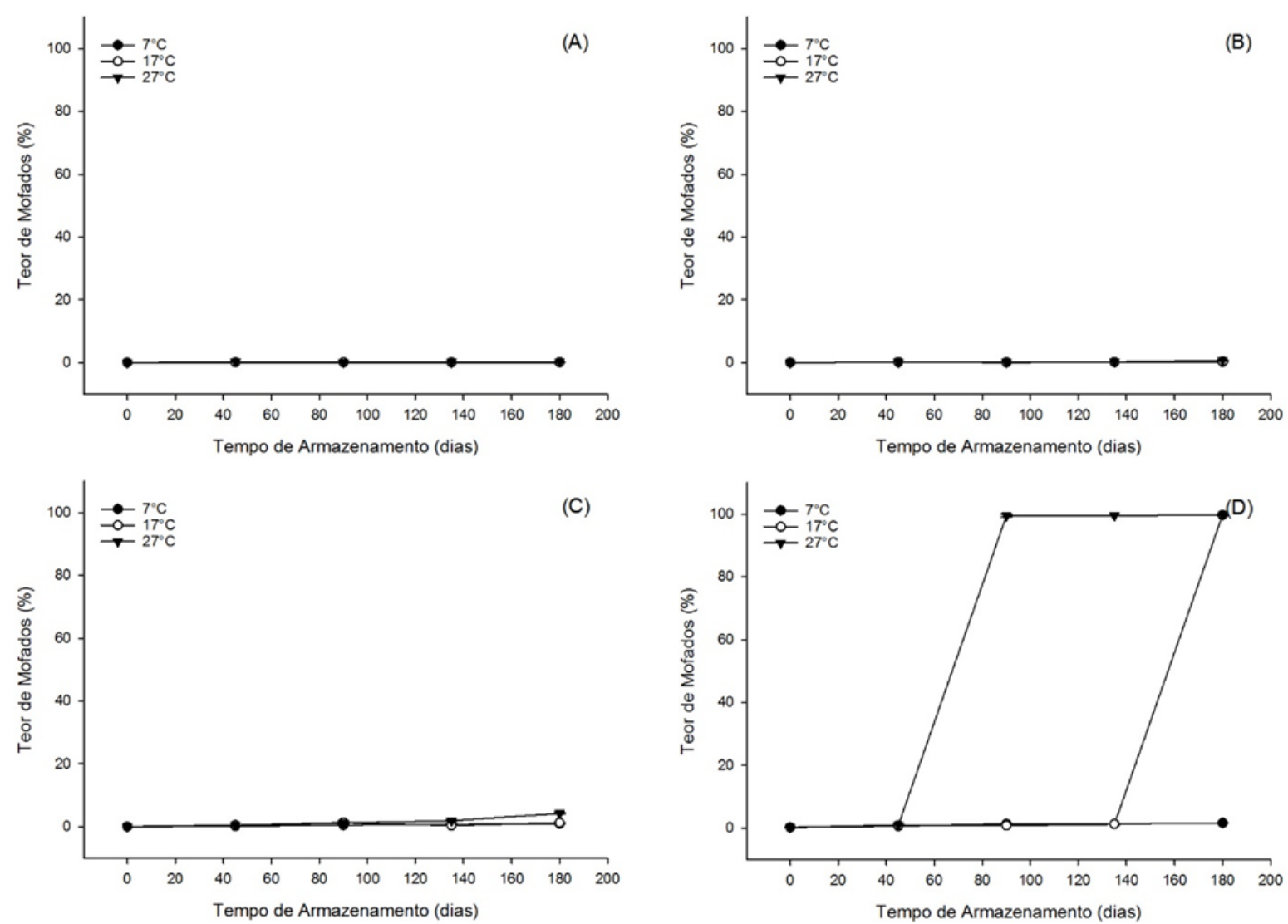

Fonte: elaborado pelo autor.

Os valores médios de $\mathrm{pH}$ obtidos dos grãos de canola armazenados durante 180 dias nas temperaturas de 7,17 e $27^{\circ} \mathrm{C}$ com umidade de $8,10,12$ e $14 \%$ (Figura 5) indicam que nos quatro teores 
de água utilizadas para armazenamento ocorreu um aumento no $\mathrm{pH}$ aos 45 dias de armazenamento e após este período ocorreu a acidificação em todas as condições estudadas.

Aos 180 dias de armazenamento, só houve diferença significativa no $\mathrm{pH}$ do tratamento a $27^{\circ} \mathrm{C}$ com teor de água $8 \%$, sendo este mais ácido em relação aos de 7 e $17^{\circ} \mathrm{C}$, e do tratamento a $7^{\circ} \mathrm{C}$ com teor de água $10 \%$, e menos ácido em relação aos de 17 e $27^{\circ} \mathrm{C}$. Nos grãos armazenados com teor de água de 12 e 14\%, aos 180 dias não houve diferença significativa entre as três temperaturas estudadas. Os resultados estão de acordo com Ziegler (2014), que armazenou soja durante doze meses e verificou que altas umidades de grãos e altas temperaturas intensificam a redução do $\mathrm{pH}$. Rehman et al. (2002) armazenando grãos de milho em três condições de temperatura verificaram redução do pH dos grãos ao final dos seis meses de armazenamento nas temperaturas de 25 e $35^{\circ} \mathrm{C}$.

Figura 5 - Efeito do tempo de armazenamento no pH de grãos de canola armazenados com teores de água de $8 \%$ (A), $10 \%$ (B), $12 \%$ (C) e $14 \%$ (D) de umidade nas temperaturas de 7,17 e $27^{\circ} \mathrm{C}$.
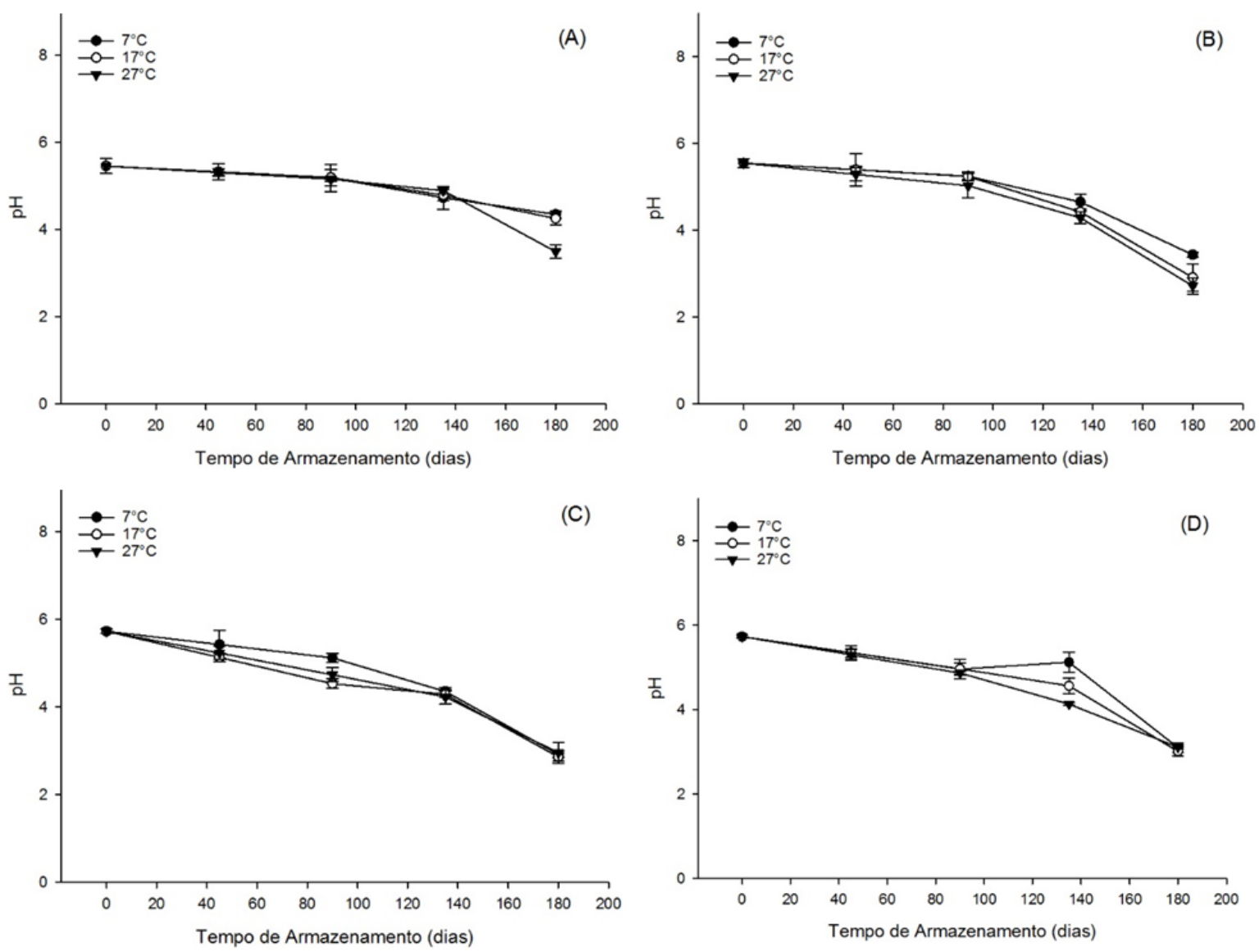

Fonte: elaborado pelo autor.

\section{Conclusão}

Portanto, as temperaturas de 17 e $27^{\circ} \mathrm{C}$ e teor de água de 12 e $14 \%$ durante 180 dias de armazenamento de grãos de canola provocaram maiores reduções nos parâmetros de perda de matéria seca e aumento na incidência de grãos mofados em comparação com as temperaturas de $7^{\circ} \mathrm{C}$. Já a temperatura de $7^{\circ} \mathrm{C}$ com teor de água de $14 \%$ durante 180 dias de armazenamento provocaram maiores reduções no peso de mil grãos e perda de matéria seca comparadas com o teor de água de $12 \%$ na temperatura de $7^{\circ} \mathrm{C}$. Assim, recomenda-se armazenar canola de forma segura durante 180 dias em temperaturas abaixo de $17^{\circ} \mathrm{C}$ com teores de água de 8 e $10 \%$. 


\section{Agradecimentos}

Gostaríamos de agradecer ao CNPq (Conselho Nacional de Desenvolvimento Científico e Tecnológico), à SCT-RS (Secretaria da Ciência, Inovação e Desenvolvimento Tecnológico do Estado do Rio Grande do Sul), à FAPERGS (Fundação de Amparo à Pesquisa do Estado do Rio Grande do Sul), ao Instituto Federal de Educação, Ciência e Tecnologia Farroupilha e à Agropecuária Trombetta de São Francisco de Assis.

\section{Referências}

ALENCAR, E. R. DE; FARONI, L. R. D.; FILHO, A, F. L.; PETERNELLI, L. A.; COSTA, A. R. Qualidade dos grãos de soja armazenados em diferentes condições. Revista Brasileira de Engenharia Agrícola e Ambiental. Campina Grande. v. 13, n. 5, p. 606-613, 2009.

ASAE - American Society of Agricultural Engineers. Moisture measurement - Unground grain and seeds, St. Joseph: ASAE, 2000. 563p.

BRASIL. Ministério da Agricultura, Pecuária e Abastecimento. Regras para Análise de Sementes. Ministério da Agricultura, Pecuária e Abastecimento, Secretaria de Defesa Agropecuária, Brasília, Mapa / ACS, p.399, 2009.

BRASIL. Ministério da Agricultura, Pecuária e Abastecimento. Instrução Normativa n 60, de 22 de dezembro de 2011. Estabelece o Regulamento Técnico do Milho. Diário Oficial [da República Federativa do Brasil], Brasília, DF, Seção 1, p.3-5, 2011.

BRASIL. Ministério da Agricultura, Pecuária e Abastecimento. Instrução Normativa n 38, de 30 de novembro de 2010. Estabelece o Regulamento Técnico do Trigo. Diário Oficial [da República Federativa do Brasil], Brasília, DF, Seção 1, p.9-10, 2010.

BRASIL. Ministério da Agricultura, Pecuária e Abastecimento. Instrução Normativa n 65, de 16 de fevereiro de 1993. Estabelece o Regulamento Técnico para o Alpiste, a Ervilha, a Lentilha, o Girassol e a Mamona. Diário Oficial [da República Federativa do Brasil], Brasília, DF,16 fev 1993.

BRASIL. Ministério da Agricultura, Pecuária e Abastecimento. Instrução Normativa $\mathrm{n}^{\circ} 11$, de 15 de maio de 2007. Estabelece o Regulamento Técnico da Soja. Diário Oficial [da República Federativa do Brasil], Brasília, DF, Seção 1, p. 3-4. 2007.

BROOKER, D. B.; BAKKER-ARKEMA, F. W.; HALL, C. W. Drying and storage of grains and oilseeds. New York: van Nostrand Reinhold, 1992. 450p.

FARONI, L. R. D. Fatores que influenciam a qualidade dos grãos armazenados, Viçosa: UFV, 1998. 15 p.

FARONI, L. R. D.; BARBOSA, G. N. O.; SARTORI, M. A.; CARDOSO, F. S.; ALENCAR, E. R.; Avaliação qualitativa e quantitativa do milho em diferentes condições de armazenamento. Engenharia na Agricultura. Viçosa, MG. v.13, n.3, 193-201, Jul./Set., 2005.

CARNEIRO, L.M.T.A.; BIAGI, J.D.; FREITAS, J.G.; CARNEIRO, M.C.; FELÍCIO, J.C. Diferentes épocas de colheita, secagem e armazenamento na qualidade de grãos de trigo comum e duro. Bragantia. Campinas. v.64, n.1, p.127-137, 2005 
PARAGINSKI, R. T.; ROCKENBACH, B. A.; SANTOS, R. F.; ELIAS, M. C.; OLIVEIRA, M. Qualidade de grãos de milho armazenados em diferentes temperaturas. Revista Brasileira de Engenharia Agrícola e Ambiental. v.19, n.4, Campina Grande, abr. 2015.

PARK, C. E.; KIM, Y. S.; PARK, K. J.; KIM, B. K. Changes in physicochemical characteristics of rice during storage at diferente temperatures. Journal of Stored Products Research, v.48, p.25-29, 2012.

PUZZI, D. Abastecimento e armazenamento de grãos. Campinas: Instituto Campineiro de Ensino Agrícola, 1999 472. $p$.

REED, C.; DOYUNGAN, S.; IOERGER, B.; GETCHELL, A. Response of storage molds to different initial moisture contents of maize (corn) stored at $25^{\circ} \mathrm{C}$, and effect on respiration rate and nutrient composition. Journal of Stored Products Research. v.43, p.443-458, 2007.

REHMAN, Z-U.; HABIB, F.; ZAFAR, S.I. Nutritional changes in maize (Zea mays) during storage at three temperatures. Food Chemistry. v.77, p.197-201, 2002.

RIOS, A. O.; ABREU, C. M. P.; CORRÊA, A.D. Efeito da estocagem e das condições de colheita sobre algumas propriedades físicas, químicas e nutricionais de três cultivares de feijão (Phaseolus vulgaris L.). Ciência e Tecnologia de Alimentos. Campinas, v. 23, p.39-45, 2003.

SANTOS, S. B.; MARTINS, M. A.; FARONI, L. R. D’A.; JUNIOR, V. R. B.; Perda de matéria seca em grãos de milho armazenados em bolsas herméticas. Revista Ciência Agronômica. v.43, n.4, Fortaleza out./dez. 2012.

SIGMAPLOT. 2015. For windows, version 13.0. Systat Software, 2015.

SILVA, J.S.; AFONSO, A.D.L.; GUIMARÃES, A. C. Estudos dos métodos se Secagem. In: Silva, J.S. Pré-processamento de produtos agrícolas. Juiz de Fora: Instituto Maria. p.105-143, 1995.

SILVA, F. de A. S. e.; AZEVEDO, C. A. V. de. Versão do programa computacional Assistat para o sistema operacional Windows. Revista Brasileira de Produtos Agroindustriais, v.4, n.1, p. 71-78, 2002.

TOMM, G.O. Sistema de Produção: Cultivo de Canola. Embrapa Trigo, 2007. Disponível em: http://www.cnpt. embrapa.br/culturas/canola/p_sp03_2007.pdf Acessado em: 20.10.2020.

ZIEGLER, V. Efeitos da umidade e da temperatura de armazenamento sobre parâmetros de avaliação da qualidade dos grãos, do óleo e de compostos bioativos de soja. 2014. 109 p. Dissertação (Mestrado em Ciência e tecnologia de alimentos) - UFPEL, Pelotas 2014. 